\title{
HAMARTOMA DO BAÇO: RELATO DE CASO E REVISÃO DA LITERATURA
}

\author{
Spleen hamartoma: case report and literature review \\ Olival Cirilo Lucena da FONSECA-NETO, Carlos Eduardo Caiado ANUNCIAÇÃO, \\ Leônidas Nogueira Gomes RABELO, Marcelo Gominho BISPO
}

ABCDDV/529

Fonseca-Neto OCL, Anunciação CEC, Rabelo LNG, Bispo MG. Hamartoma do baço: relato de caso e revisão da literatura. ABCD Arq Bras Cir Dig 2007;20(1):68-70.

RESUMO - Introdução- Hamartoma do baço é uma lesão incomum. Cerca de cento e cinqüenta hamartomas esplênicos foram descritos na literatura. Relato do caso - Mulher com 54 anos queixava-se de sensação de empachamento e aumento do volume abdominal há dois anos. Negava vômitos e alterações do ritmo intestinal, assim como, perda de peso. Ao exame físico foi observado bom estado geral, abdome flácido, doloroso à palpação profunda em hipocôndrio esquerdo, massa palpável à cerca de $8 \mathrm{~cm}$ do rebordo costal esquerdo, ruídos hidroaéreos presentes. Os resultados dos exames laboratoriais foram normais Tomografia computadorizada de abdome demonstrou baço aumentado de volume devido à volumosa formação expansiva, heterogênea, com conteúdo predominantemente hipodenso (cístico) e septação grosseira com focos de calcificação de permeio medindo aproximadamente $14,0 \times 16,0 \times 12,0 \mathrm{~cm}$ nos diâmetros longitudinal, ântero-posterior e transverso respectivamente. A paciente foi submetida à laparotomia exploradora onde não foram observados implantes tumorais na cavidade peritoneal e esplenectomia foi realizada sem intercorrências. $\mathrm{O}$ exame macroscópico da peça operatória mostrava baço aumentado de volume, pesando $1170 \mathrm{~g}$ e medindo 23,0 x 14,5 x 10,0 cm, chamando atenção uma volumosa massa de 14,5 x 10,0 cm. Exame histopatológico com imunoistoquímica concluiu tratar-se de tecido hamartomatoso e ausência de malignidade. Conclusão - O hamartoma é tumor benigno raro, mas deve ser lembrado no diagnóstico diferencial de massas originadas do baço, e a esplenectomia pode ser realizada de forma segura e eficaz.

DESCRITORES - Hamartoma. Baço. Esplenoma

\section{INTRODUÇÃO}

Hamartomas do baço são tumores muito raros.4,19 Descritos inicialmente por Rockitansky e Fhriedreich em 1861, encontram-se apenas cento e cinqüenta casos na literatura ${ }^{14}$. São na sua maioria assintomáticos sendo diagnosticados ao acaso ou em autópsias. Entretanto, é comum a sua associação com alterações hematológicas, como anemia microcítica refratária, esferocitose hereditária e anemias hemolíticas ${ }^{6}$. Manifesta-se como nódulo único ou múltiplo às vezes difíceis de serem diferenciados do parênquima normal (porção não linfóide) ${ }^{1}$. São caracterizados por proliferação de histiócitos, fibrose e áreas de calcificação. O diagnóstico diferencial é feito principalmente com os tumores benignos do baço ${ }^{11}$.

\section{RELATO DO CASO}

MLFS, sexo feminino, 54 anos, lavadeira, era acompanhada em serviço regional sem diagnóstico, queixandose de sensação de empachamento e aumento do volume abdominal há dois anos. Negava vômitos e alterações

Trabalho realizado no Serviço de Cirurgia Geral e do Trauma do Hospital da Restauração - SUS, Recife, PE, Brasil.

Endereço para correspondência: Olival Cirilo Lucena da Fonseca Neto, e-mail: olivalneto@globo.com do ritmo intestinal, assim como, perda de peso. Referia dispnéia aos esforços e cefaléia ocasional. Apresentava hipertensão arterial e fazia uso irregular de captopril e hidroclorotiazida. Era portadora de asma brônquica e não realizava tratamento. Antecedentes negativos para etilismo e tabagismo. Ao exame físico foi observado bom estado geral e nenhuma alteração no aparelho cardiovascular e respiratório. $\mathrm{O}$ abdome era pouco globoso, flácido, doloroso à palpação profunda em hipocôndrio esquerdo, ruídos hidroaéreos presentes e tinha massa palpável à cerca de $8 \mathrm{~cm}$ do rebordo costal esquerdo. Os resultados dos exames laboratoriais foram normais (ausência de hiperesplenismo, sorologias virais negativas). A tomografia computadorizada de abdome foi realizada e demonstrou baço aumentado de volume devido à volumosa formação expansiva, heterogênea, com conteúdo predominantemente hipodenso (cístico) e septação grosseira com focos de calcificação de permeio medindo aproximadamente 14,0 x 16,0 x 12,0 cm nos diâmetros longitudinal, ântero-posterior e transverso respectivamente (Figura 1), sendo a sua natureza impossível de ser estabelecida baseada apenas em dados fornecidos por exames radiológicos. A possibilidade da massa ser de origem neoplásica foi aventada. A paciente foi submetida à laparotomia exploradora onde não foi observado implante tumoral na cavidade peritoneal e esple- 
nectomia total foi realizada sem intercorrências (Figura 2). No pós-operatório a sua evolução foi sem complicações recebendo alta no $5^{\circ}$ dia de pós-operatório. O exame macroscópico da peça operatória mostrava baço aumentado de volume, pesando $1170 \mathrm{~g}$ e medindo 23,0 x 14,5 x 10,0 cm, chamando atenção uma volumosa massa de 14,5 x 10,0 cm. $\mathrm{O}$ restante do parênquima estava preservado sem adenomegalias hilares. Laudo da microscopia revelou acúmulos de material amorfo acidófilo de natureza não determinada com áreas de hemorragia. Como hipóteses diagnósticas iniciais foram propostas amiloidose (apesar do material não se corar com vermelho congo) e linfangioma. Estudo complementar com imunoistoquímica concluiu tratar-se de massa nodular bem delimitada composta de tecido hamartomatoso constituído essencialmente por padrão de polpa vermelha com focos de hematopoiese e extensas áreas de degeneração isquêmica, gelatinosa, tipo "infarto-lento" e ausência de sinais de malignidade.

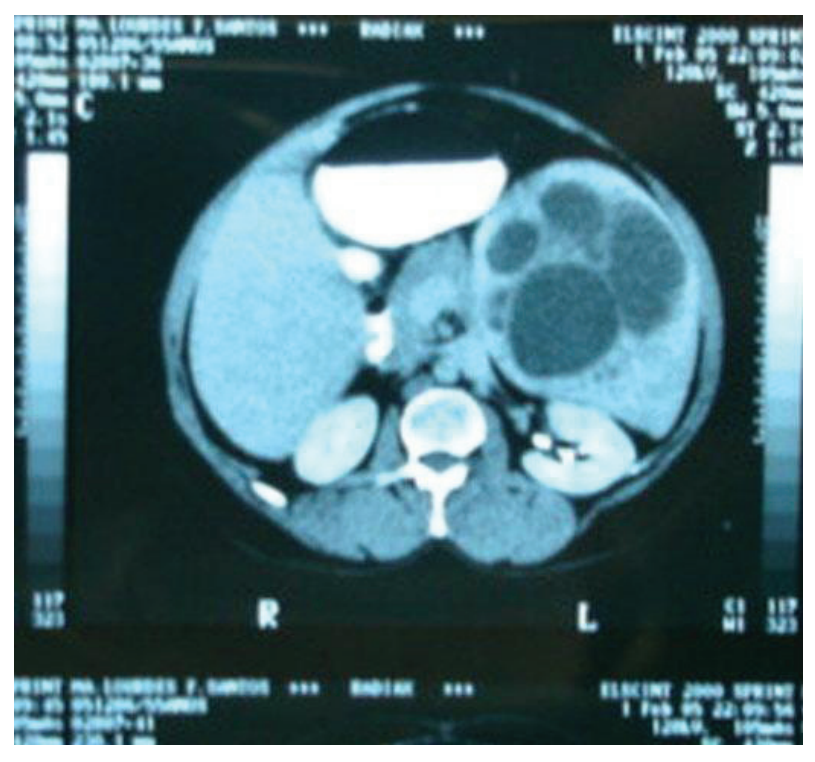

FIGURA 1 - Tomografia computadorizada de abdome mostrando massa esplênica heterogênea

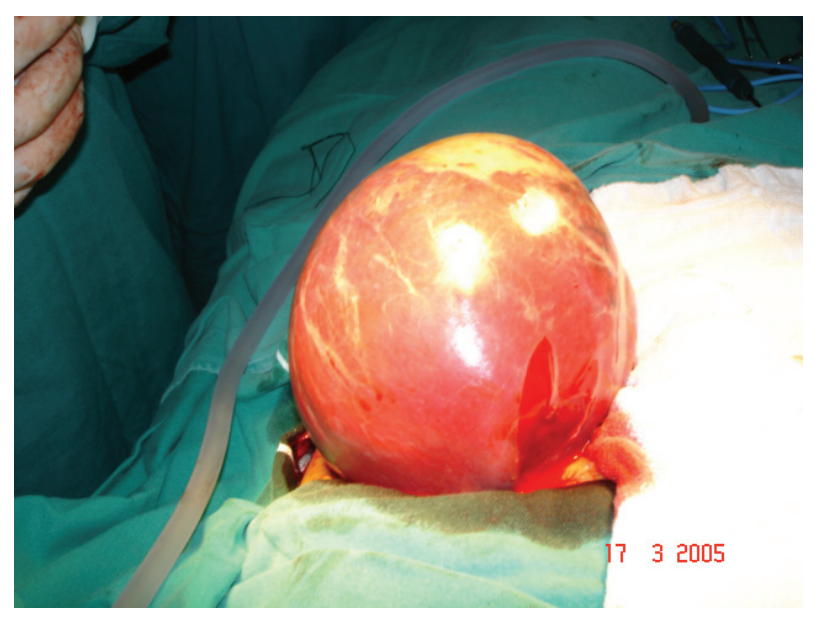

FIGURA 2 - Massa esplênica fora da cavidade abdominal durante o procedimento cirúrgico

\section{DISCUSSÃO}

Hamartoma esplênico é lesão incomum ${ }^{4,19}$.O seu aparecimento já foi identificado em todas as faixas etárias e não existe preferência pelo sexo ${ }^{2}$. Por ser entidade rara, a sua documentação gera vários relatos de caso e pequenas séries. Esplenoma, hiperplasia nodular do baço, esplenoadenoma, splenunculus intra-esplênico são outros termos utilizados para hamartoma do baço.

A incidência em autópsias varia entre $0,024 \%$ a $0,13 \%$. Silverman e Li Volsi ${ }^{17}$ descreveram três casos de hamartoma esplênico entre 200.000 biópsias cirúrgicas (incluindo esplenectomias e outras biópsias) após o período de 17 anos $^{2,17}$. Lam, Yip e Peh também demonstraram três casos em 380.000 biópsias cirúrgicas após período de 25 anos $^{3}$.

Não há relato na literatura da incidência do hamartoma com outras lesões do baço. Existe associação dele com neoplasias ${ }^{18}$ e com aparecimento de doença proliferativa.

A apresentação clínica dos hamartomas do baço geralmente é silenciosa ${ }^{6}$.O aparecimento de dor abdominal inespecífica, a presença da febre de origem obscura e queixas urinárias já foram descritas associadas a esse tumor $^{3,16}$. A ruptura espontânea causando quadro agudo de hemoperitônio também já foi relatado na literatura ${ }^{8}$.A associação de trombocitopenia, anemia e leucopenia é muito referida na maioria dos relatos. No entanto, o diagnóstico incidental de massa esplênica em check-up clínico pode ocorrer e dependendo da sua apresentação radiológica o hamartoma pode fazer parte do diagnóstico.

Ao exame ultrassonográfico a massa esplênica apresenta-se homogênea e sólida com ecogenicidade relativa quando comparada com o parênquima esplênico normal ${ }^{20}$. No entanto, usualmente são massas hipoecogênicas. Pode ocasionalmente encontrarem-se cistos ou núcleos de calcificação. A utilização do ultrassom Doppler poderá demonstrar a intensa vascularização desses tumores ${ }^{9}$.

A tomografia computadorizada de abdome poderá definir estar a lesão circunscrita ao órgão e sugerir a radicalidade da operação ${ }^{10}$. A ressonância nuclear magnética também já foi utilizada para aprimorar o diagnóstico, no entanto, parece não oferecer detalhes a mais que os outros exames de imagem ${ }^{5,13,15}$.

A indicação cirúrgica é precisa. A esplenectomia total pode ser realizada a céu aberto ou por videolaparoscopia $^{21}$.

No exame histopatológico encontram-se canais vasculares tortuosos arrumados irregularmente no seio esplênico ${ }^{7}$. A arquitetura de reticulina está desorganizada em relação ao parênquima normal ${ }^{12}$.

\section{CONCLUSÃO}

O hamartoma esplênico é um tumor benigno que deve ser lembrado no diagnóstico diferencial de massas originadas do baço, e a esplenectomia pode ser realizada como atitude terapêutica segura e eficaz. 
Fonseca Neto OCL, Anunciação CEC, Rabelo LNG, Bispo MG. Spleen hamartoma: case report and literature review. ABCD Arq Bras Cir Dig 2007;20(1):68-70.

ABSTRACT - Background - Spleen Hamartoma is an uncommon lesion. Approximately one-hundred and fifty spleenic hamartomas have been described in literature. Case report - A 54 year-old woman complained of full stomach sensation and increased abdominal volume for two years. She denied vomiting or having any intestinal alteration, as well as no weight loss. Upon physical examination, an overall good state of health was observed, except for a flacid abdomen, painful upon deep palpation in the left hyponchondrium area, showing a palpable mass at approximately $8 \mathrm{~cm}$ from the left costal arch, as well as hidroairy sounds. Laboratory exams showed no alterations. Computerized tomography of the abdomen showed an increased volume of the spleen due to an expansive volumous formation, heterogeneous, containing a hypodense (cystic) liquid and rough septation with underlying calcifications foci measuring about $14,0 \times 16,0 \times 12,0 \mathrm{~cm}$ in diameters longitudinally, antero-posteriorlly and transversally respectively. The patient was submitted to exploratory laparotomy, where no tumors in the peritoneal cavity were observed, allowing spleenectomy to be persued without interventions. Macroscopic exams of the surgical segment showed an increased spleen, weighing 1,170 and measuring 23,0 $\mathrm{x} 14,5 \times 10,0 \mathrm{~cm}$. The attention was called to a volumous mass weighing $14,5 \times 10,0 \mathrm{~cm}$. Through hystopathological and immunohistochemical exams, it was concluded that the mass was an hamartomous tissue without any malignancy. Conclusion - The harmartoma is a benign rare tumor, nevertheless it should be recalled during differential diagnosis of unknown masses originated in the spleen, making spleenectomy a safe and effective procedure.

HEADINGS - Hamartoma. Spleen. Splenoma.

\section{REFERÊNCIAS}

1. Abramowsky C, Alvarado C, Wyly JB, et al. 'Hamartoma' of the spleen (splenoma) in children. Pediatr Dev Pathol 2004; 7:231-236.

2. Berge TH. Splenoma. Acta Pathol. Microbiol. Scand. 1965; 63:333-9.

3. Bhagwat AG, Datta DV, Mitra S, Aikat BK. Splenoma with portal hypertension . Br Med J 1975; 30:520-521.

4. Buchler M, Al-Najjar A, Guerraaoui A et al. Appearance of múltiple progressive nodules in the spleen of a renal graft recipient. Nephrol. Dial. Transplant 1997; 12:1739-41.

5. Butler JJ. Pathology of the spleen in benign and malignant conditions. Histopathology 1983; 7:453-74.

6. Cheuk W, Lee AKC, Arora N, Ben-Arie Y, Chan JKC. Splenic hamartoma with bizarre stromal cells. Am J Surg Pathol 2005; 29:109-114.

7. Falk S, Stutte HJ. Hamartomas of the spleen: a study of 20 biopsy cases. Histopathology 1989; 14:603-612.

8. Ferguson ER, Sardi A, Beckman EN. Spontaneous rupture of splenic hamartoma. J La State Med Soc 1993; 145:48-52.

9. Goerg C, Schwerk WB. Color doppler imaging of focal splenic masses. Eur J Radiol 1994; 18:214-219.

10. Ha HK, Kim HH, Kim BK, Han JK, Choi BI. Primary angiosarcoma of the spleen. CT and MR imaging. Acta Radiol 1994; 35:455-458.

11. Kraus MD, Dehner LP. Benign vascular neoplasms of the spleen with myoid and angioendotheliomatous features. Histopathology 1999; 35:328-336.

12. Krishnan J, Frizzera G. Two splenic lesions in need of clarification: hamartoma and inflammatory pseudotumor. Semin Diagn Pathol 2003; 20:94-104.
13. Lam KY, Yip KH, Peh WCG. Splenic vascular lesions: unusual features and a review of the literature. Aust. N. Z. J. Surg. 1999; 69:422-425.

14. Nakanishi S, Shiraki K, Yamamoto K, Nakano T, Koyama M, Yano T, Sanda T, Tamaki H, Hirano T, Fukudome K, Ishihara A. Basket pattern blood flow signals discovered in a case of splenic hamartoma by power doppler ultrasonography. World J Gastroenterol 2005; 11(33):5235-5238.

15. Ohtomo K, Fukuda H, Mori K, Minami M, Itai Y, Inoue Y. CT and MR appearances of splenic hamartoma. J Comput Assist Tomogr 1992; 16:425-428.

16. Seyama Y, Tanaka N, Suzuki Y, Nagai M, Furuya T, Nomura Y, Ishii J, Nobori $\mathrm{M}$. Spontaneous rupture of splenic hamartoma in a patient with hepatitis $\mathrm{C}$ virus-related cirrhosis and portal hypertension: A case report and review of the literature. World J Gastroenterol 2006; 12(13):2133-2135.

17. Silverman ML, Li Volsi VA. Splenic hamartoma. Am. J. Clin. Pathol. 1978; 70:224-9.

18. Steinberg JJ, Suhrland M, Valensi Q. The spleen in the spleen syndrome: the association of splenoma with hematopoietic and neoplastic disease-compendium of cases since 1864. J. Surg. Oncol. 1991; 47:193-202.

19. Sweet RH, Warren S. Hamartoma of the spleen, report of a case. N. Engl. J. Med. 1942; 226:757-8.

20. Tang S, Shimizu T, Kikuchi Y, Shinya S, Kishimoto R, Fujioka Y, Miyasaka K. Color doppler sonographic findings in splenic hamartoma. J Clin Ultrasound 2000; 28:249-253.

21. Yoshizumi T, Iso Y, Yasunaga C, Kitano S, Sugimachi K. Laparocospic splenectomy for splenic hamartoma. Surg Endosc 1997; 11:848-849.

Conflito de interesse: não há Fonte financiadora: não há Recebido para publicação em: 07/07/2006 Aceito para publicação em: 17/11/2006 